\title{
REAÇÃo dE TRANSESTERIFICAÇÃo DO ÓLEO DE GIRASSOL E ETANOL PARA A PRODUÇÃO DE BIODIESEL EM MICROREATORES
}

\author{
Osvaldir P. Taranto (PQ), Harrson S. Santana (PG), Érica M. Reis (PG), Deborah S. Tortola (IC). \\ Resumo
}

A transesterificação de óleos vegetais com alcoóis é o método mais utilizado na síntese de biodiesel, geralmente ocorrendo em batelada. Porém, atualmente essa produção vem sendo explorada em microreatores, devido aos seus curtos tempos de residência com elevadas conversões. Em virtude disso, esse trabalho estudou a síntese de biodiesel em microreatores a partir do óleo vegetal de girassol e etanol utilizando como catalisador hidróxido de sódio. Na síntese do biodiesel foi estudada a influência das variáveis: temperatura, razão etanol/óleo e concentração do catalisador. Foi feita uma comparação entre os métodos de reação em batelada e em microreatores. A máxima porcentagem de biodiesel encontrada para a reação em batelada e em microreatores foi de $88 \%$ e $95,8 \%$, respectivamente. Os resultados comprovaram a eficiência dos microreatores na síntese de biodiesel.

Palavras Chave: biodiesel, transesterificação, microreatores.

\section{Introdução}

O aumento da preocupação com o meio ambiente impulsionou o uso de fontes renováveis, como o biodiesel. Esse biocombustível apresenta notáveis vantagens, que o torna ambiental, social e economicamente interessante ${ }^{1}$.

Atualmente, a produção de biodiesel ocorre por batelada, porém, visando otimizar esse processo, a microfluidica tem ganhado espaço, apresentando vantagens tais como curto tempo de residência e elevadas conversões. Nesse sentido, esse estudo tem como objetivo estudar a síntese de biodiesel em microreatores a partir do óleo vegetal de girassol e etanol utilizando como catalisador hidróxido de sódio.

\section{Resultados e Discussão}

Os experimentos foram realizados em dois sistemas experimentais: o sistema em batelada e utilizando microreatores. Os resultados obtidos são mostrados na Figura 1. As maiores porcentagens de ésteres etílicos (FAEE) obtidas para o reator batelada e para o microreator foram de $88 \%$ e 95,8\%, respectivamente. Esse resultado provavelmente está associado ao reduzido comprimento de escala do microreator, o que permite obter altas taxas de transferência de massa e calor, elevada área superficial em relação ao volume e um curto comprimento de difusão dos reagentes, quando comparados aos reatores convencionais ${ }^{2}$.

Em relação às variáveis estudadas, nota-se que a FAEE no microreator aumenta: à altas temperaturas, pois há acréscimo na miscibilidade entre etanol e óleo; ao aumentar a razão molar etanol/óleo até a razão (14:1); ao aumentar a concentração de catalisador de $0,25 \%$ a $0,75 \%$.
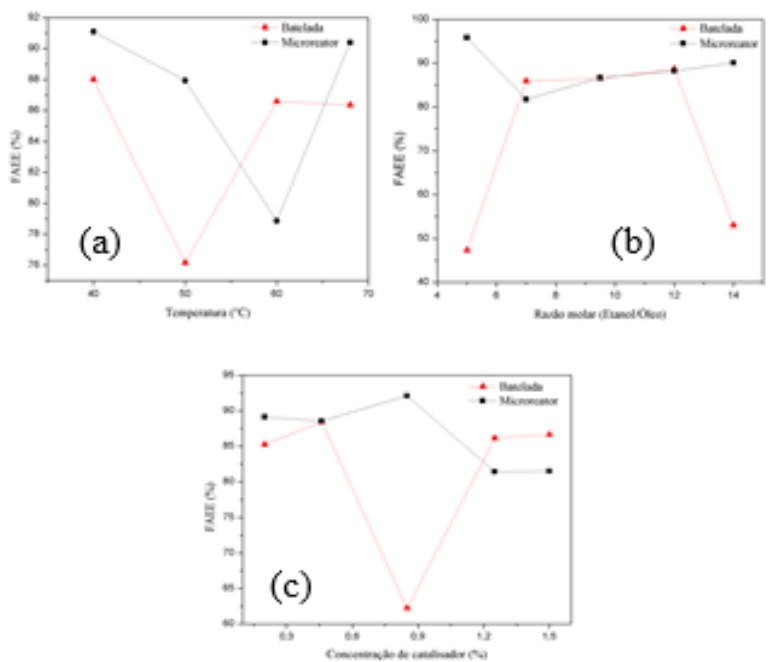

Figura 1. Efeito das variáveis na $\operatorname{FAEE~(\% ):~(a)~}$ Temperatura; (b) Razão molar e (c) Concentração de catalisador.

\section{Conclusões}

A máxima porcentagem FAEE obtida para 0 reator batelada e para o microreator foi de $88 \%$ e $95,8 \%$, respectivamente. Pode-se concluir que os microreatores são uma opção viável para a produção de biodiesel.

\section{Agradecimentos}

FAPESP, CAPES, CNPQ.

\footnotetext{
MIRANDA, J.C.C.; Criação do banco de dados, simulação e análise energética do processo de produção de biodiesel de soja, mamona e pinhão manso; Campinas, Universidade Estadual de Campinas, 2011.

${ }^{2}$ WHITESIDES, G.M. The origins and the future of microfluidics

Nature, v. 442, p. 386-373, 2006.
} 